\title{
Comparing coding between interventional radiologists and hospital coding departments
}

\author{
This article was published in the following Dove Press journal: \\ Clinical Audit \\ 22 May 2010 \\ Number of times this article has been viewed
}

\section{J Cox'}

\section{N Koutroumanos'}

'Department of Radiology, University Hospital North Durham, Durham, UK

Correspondence:J Cox

Consultant Radiologist, Department

of Radiology, University Hospital

North Durham, North Rd,

Durham, DHI 5TW, UK

Tel +44 I9I 333 249I

Email julie.cox@cddft.nhs.uk
Purpose: The purpose of this audit was to assess whether there was a difference in the health care resource groups coding and subsequent reimbursement of interventional radiology cases, depending on whether the coding was carried out by a clinician or an administrator in the coding department

Methodology: A retrospective analysis was undertaken of 137 consecutive patients who had therapeutic endovascular procedures in our Trust from 2005-2007. Six patients were excluded due to lack of data. The audit was carried out at a single center. A single clinician, under the supervision of a consultant interventional radiologist, proceeded to code the procedure after referring to the patient's radiology report and notes.

Findings: The error rate by part of the coding department in terms of assessing nonelective versus elective procedures was $7 \%$. This had lead to a $£ 2,352$ excess charge on the part of the coding department. Additionally, there were errors in a further 19 procedures $(15 \%)$, in which vascular stents had been inserted during the procedure but had not been coded for. The stent usage had not been recognised by the coding administrators in their evaluation, and this equipment-based undercoding resulted in underpayment by the patient's primary care trust of $£ 11,153$.

Originality/value: This is the first published audit of coding in interventional radiology in the UK. Coding in complex subspecialties like vascular interventional radiology requires more clinical input and engagement to ensure the case complexity is accurately reflected in the codes assigned and in the subsequent reimbursement.

Keywords: coding, interventional radiology, payment by results (PBR)

\section{Introduction}

In April 2004 the UK Department of Health (DH) introduced new reforms proposing payment by results (PBR). Using this system, health care providers are reimbursed by levels of activity (number of cases) adjusted for by case mix (complexity and variety of cases) instead of block contracts. ${ }^{1}$

The new payment system uses health care resource groups (HRGs) as a measure of the care, based on both the diagnosis and the complexity of treatment. The HRGs are similar to those used in Europe, North America, and Australia. Their purpose is to group together similar clinical treatments which should cost an equivalent amount to deliver. This system aims primarily to provide a structure of a national fixed tariff, with a secondary aim to improve productivity and increase capacity throughout the NHS. An individual tariff, representing the average cost of a procedure, is assigned to each hospital episode to be funded by the patient's primary care trust (PCT). ${ }^{2}$ 
HRG codes are combined from a combination of diagnostic (ICD 10) and procedure (OPS) codes which are derived from the patient's records. The consequence of a patient being given the wrong OPS code will result in an incorrect HRG code and therefore an incorrect tariff payment. ${ }^{3}$

The difficulty in the PBR system is that in some cases, the HRG codes are extremely broad (and in some cases outdated) and do not allow for finer discrimination between complex procedures. For example, within the rapidly evolving subspecialty of vascular interventional radiology, there are currently only two HRG codes presently in use to describe, categorise, and provide reimbursement for all procedures:

Q12 for therapeutic endovascular procedures.

Q14 for diagnostic radiology.

Also, certain medical devices used in interventional radiology, such as carotid, iliac, and renal stents, attract additional payment over and above the tariff, to cover the device costs. $^{4}$

\section{Purpose}

The purpose of this audit was to assess whether there was any difference in the coding and subsequent reimbursement of interventional radiology cases depending on whether the coding was carried out by clinicians or by administrators in the coding department. The identification of the rate of discrepancies, and the subsequent difference in reimbursement, between the two sets of coders were defined as the two endpoints of the audit.

\section{Methodology}

A retrospective audit was undertaken of 137 consecutive procedures which had therapeutic endovascular procedures (coded as HRG Q12) in our Trust from 2005-2007. Six patients were excluded due to lack of data. The audit was carried out at two hospital sites within the same National Hospital Service (NHS) trust. A clinician training in radiology (NK), under the direct supervision of a consultant interventional radiologist (JC), proceeded to code the procedure after referring to the patient's report and notes. The clinical coder (NK) was blinded to the results of the nonclinical coder's assessment of the coding for each case.

Data for clinical coding was obtained from both a review of the patient's radiology request card and a review of the case notes, and the procedure was categorized as elective or nonelective based on the information available. The clinical coder had the same sources and opportunities for information extraction (the case notes) as the original nonclinical coders.
Information was obtained from the hospital coding department about the HRG code assigned to the patients by the nonclinical coders and the charge made through the hospital finance department to the Primary Care Trust.

\section{Findings}

A total of 137 consecutive patients were identified who had therapeutic endovascular procedures (HRG Q12) between April 2005 and March 2008 at two hospital sites within the same NHS trust.

The HRG code and tariff for elective and nonelective procedures as defined by the Department of Health is shown in Table 1.

Table 2 summarizes the results of the audit and discrepancies between clinical and nonclinical coders.

Overall, the error rate in terms of defining the urgency of the procedures (elective versus nonelective) was $7 \%$ on the part of the coding department, for the cases which had been assigned tariffs of HRG Q12. Nine out of 131 cases had been coded incorrectly: four nonelective cases had been categorized as emergencies, and five elective cases had been categorized as nonelective. This had lead to a $£ 2,352$ excess charge on the part of the coding department.

Additionally, there were errors in the nonclinical coding of a further 19 procedures (15\%). Although correctly coded as HRG Q12, vascular stents inserted during the procedure had not been included by the nonclinical coders. The stents represent additional equipment usage, which attracts reimbursement at an average cost of about $£ 500+$ VAT, and would have resulted in underpayment by the fundholder, the PCT, of $£ 11,153$.

\section{Discussion: value of findings}

Previous audits of coding have shown a wide variety of error rates when the performance of a nonclinical coder has been compared to that of a clinician. This does raise the salient and highly debatable point of who is correct? In the United Kingdom, it is often implicitly assumed to be the clinician, while in the literature from the United States, in contrast, clinician coding performance is generally judged against the

Table I HRG code and tariff for therapeutic endovascular procedures $^{5}$

\begin{tabular}{|c|c|c|c|}
\hline $\begin{array}{l}\text { HRG } \\
\text { code }\end{array}$ & HRG name & $\begin{array}{l}\text { Elective spell } \\
\text { tariff }(£)\end{array}$ & $\begin{array}{l}\text { Nonelective spell } \\
\text { tariff }(£)\end{array}$ \\
\hline \multirow[t]{3}{*}{$\mathrm{Q} 12$} & Therapeutic & $\mathrm{I}, 108$ & 3,460 \\
\hline & Endovascular & & \\
\hline & Procedures & & \\
\hline
\end{tabular}

Abbreviation: HRG, health care resource groups. 
Table 2 Results of interventional radiology coding audit

\begin{tabular}{llllll}
\hline & Radiologist & $\begin{array}{l}\text { Cost as calculated by } \\
\text { radiologist under PBR (£) }\end{array}$ & Coding & $\begin{array}{l}\text { Cost as calculated by } \\
\text { coder under PBR (£) }\end{array}$ & Cost excess by coders (£) \\
\hline Elective & 108 & 119664 & 107 & 118556 \\
Nonelective & 23 & 79580 & 24 & 83040 & 2352 \\
Total & 131 & 199244 & 131 & 201596 & 235 \\
\hline
\end{tabular}

Note: Total cohort $\mathrm{n}=|3|$.

Abbreviation: PBR, payment by results.

professional nonclinical coder, who is deemed to represent the gold standard.

Within the UK-based literature, there are a number of audits carried out in recent years from subspecialties in which the performance of clinical coders is compared with nonclinical coders. A large, recent, coding audit of 1250 otolaryngology inpatient and day-surgery cases demonstrated coding errors in $24.1 \%$ of cases $(301 / 1250)$, which may reflect the variety and complexity of the case mix of the cases examined in that paper. Of interest, the total cost of maintaining a cliniciancoder was 4.8 times lower than the income regained through the double-reading process, suggesting that it may well be worthwhile financially for trusts to engage and support clinicians' involvement in coding. ${ }^{6}$

Another recent UK-based audit comparing clinical and nonclinical coding of consecutive major head and neck operations over a 3-month period demonstrated similar discrepancies. The number of procedure codes generated initially by the clinical coders was 99, whereas the revised coding generated 146. Of the original codes, 47 of 99 (47.4\%) were incorrect. In 19 of the 34 cases reviewed (55.9\%), the HRG code remained unchanged, thus resulting in the correct payment. Six cases were never coded, equating to $£ 15,300$ of underpayment. ${ }^{7}$

In a coding audit carried out analyzing 276 day case ENT patients, coding errors or discordance occurred in 89 patients, ( $32 \%$ of the total number). Of these episodes the new revised coding based on the clinician's assessment attracted a higher tariff in $67(75 \%)$ cases. $^{3}$

With regard to the coding of interventional radiology procedures, there have been no published audits from the UK to date. In the US, where accurate coding has long been perceived as vital, and nonclinical coders have their own career path and qualifications, coding is more of an exact science. In the United States, the 'experts' are usually deemed to be the nonclinical professional coders, whereas the practicing physician is the individual whose coding error rate is assessed. This approach to audit is exactly the opposite of that usually taken in the UK.

There have been several papers published from the US which assess the accuracy of radiologist coding of interventional radiology procedures, compared with expert (or nonclinical) coders.

A large study to evaluate the accuracy of current procedural terminology (CPT) coding for interventional radiology procedures, carried out in 2004, obtained information from 549 interventional radiology encounters, performed by 62 radiologists at 23 hospitals, and analyzed for appropriate CPT code use. CPT codes selected by medical staff were reviewed by nonclinical coding experts, who determined correct coding by consensus. Radiologists coded correctly 242 of 549 interventional radiology cases (44\%). Experts (ie, nonclinicians) were initially concordant in 497 of 549 cases $(91 \%)$, with only a minimal tendency towards overcoding. Expert coding differences were explained by simple code oversights, coding guideline ambiguity, and physician documentation ambiguity. ${ }^{8}$

A second large audit involved evaluating coding data for 1,174 interventional radiology encounters in 736 patients. CPT codes from physicians were compared with experienced interventional radiology physician coders. In this audit, $82 \%$ of encounters were initially coded correctly by the physician coders, with a small net tendency toward under-coding. The overall net errors were only minor, and more complex cases were much more likely to be coded erroneously than less complex cases. Experienced physician coders committed significantly fewer errors than other physicians. ${ }^{8}$

This perception of underpayment as a result of under-coding is not entirely without issues. PCT commissioners are also concerned about the level of errors in coding, and also about the implication that foundation trusts are faced with financial incentives to (code up) activities, a phenomenon referred to as 'HRG drift'. Thus far there is little conclusive evidence of HRG drift, but HRG codes require continual updating, and the coding process as a whole requires rigorous audit. ${ }^{9} \mathrm{Certainly}$, our audit demonstrates slight over-coding by nonclinical coders, as well as a lack of recognition of the additional equipment used in the procedures, resulting in $£ 8,800$ of underpayment in a two-year period. This is not consistent with a pattern of HRG drift.

In 2007, the Royal College of Radiologists, together with the NHS information authority, has attempted to improve 
the situation by developing new HRGs, as a result of an expert working group. Using their considerable expertise, the working group, containing senior interventional radiologists, developed six HRG bands covering interventional radiology procedures, with remuneration ranging from $£ 500-£ 30,000 .^{10}$

Also, from April 2009, interventional radiology procedures are now to be 'unbundled' from the main tariffs. Currently interventional radiology procedures may account for much of the patient's treatment, but they are not reimbursed separately from the patient's whole stay. The HRG design includes a whole new section (chapter HRB) which is intended to enable interventional radiology procedures to be separately identified (unbundled from the core HRG). There are now ten interventional radiology-specific unbundled HRGs. ${ }^{11}$ This development is promising, and should improve the specialty's funding and prominence, but it also adds increasing complexity, and will require strong clinician engagement to ensure the coding is accurate.

Limitations of this audit are chiefly that there was only one clinical, and one nonclinical coder. We have assumed the clinical coder to be the more accurate of the two, but, ideally, to assess interobserver variation, the performance of both coders should have been compared with at least one other clinical, and one nonclinical coder.

\section{Conclusion}

At present, coding in complex subspecialties like vascular interventional radiology, requires more clinical input and engagement, to ensure that the case complexity is accurately reflected in the codes assigned, and in the subsequent reimbursement. The development in the UK of even more complicated unbundled HRGs for interventional radiology should improve funding within the specialty, but will require clinicians in the subspecialty to play a far more active role in the coding process.

\section{Disclosure}

The authors report no conflicts of interest in this work.

\section{References}

1. Department of Health. Reforming NHS financial flows: Introducing payment by results. 2002. Available from: http://www.dh.gov.uk/en/ Consultantions/Closedconsultantions/DH_4016901. Accessed 2009 May 5.

2. Jameson S, Reed MR. Payment by results and coding practice in the National Health Service: the importance for orthopaedic surgeons. J Bone Joint Surg. 2007:89:1427-1430.

3. Joy R, Velagala S, Akhtar S. Coding: an audit of its accuracy and implications. Ann R Coll Surg Engl Suppl. 2008;90:284-285.

4. Department of Health. Payment by results. 2008. Available from http:// www.dh.gov.uk/en/Managingyourorganisation/Financeandplanning/ NHSFinancialReforms/index.htm. Accessed 2008 November 24.

5. Nouraei SA, O'Hanlon S, Butler CR, et al. Multidisciplinary audit of clinical coding accuracy in otolaryngology: financial, managerial and clinical governance considerations under payment-by-results. Clin Otolaryngol. 2009;34:43-51.

6. Mitra I, Malik T, Homer JJ, Loughran S. Audit of clinical coding of major head and neck operations. Ann R Coll Surg Engl. 2009;91:245-248.

7. Duszak R, Blackham WC, Kusiak GM, Majchrzak J. CPT coding by interventional radiologists: a multi-institutional evaluation of accuracy and its economic implications. J Am Coll Radiol. 2004;1:734-740.

8. Duszak R Jr, Sacks D, Manowczak J. CPT coding by interventional radiologists: accuracy and implications. J Vasc Interv Radiol. 2001;12:447-454.

9. Rogers R, Williams S, Jarman B, Aylin P. 'HRG drift' and payment by results. BMJ. 2005;330(7491):563.

10. BIBA Medical. Payment by results: Radiologists need to Intervene. Interventional News. 2007. Available from http://www.cxvascular.com/ in-archives/interventional-news-21/payment-by-results-radiologistsneed-to-intervene. Accessed 2009 June 1.

11. National Hospital Service. Ten Top Tips for HRG 4. 2009. Available from http://www.ic.nhs.uk/services/casemix/hrg4/ten-top-tips-for-hrg4. Accessed 2009 June 1.
Clinical Audit

\section{Publish your work in this journal}

Clinical Audit is an international, peer-reviewed, open access journal focusing on the processes and outcomes of clinical audit in any area of healthcare. All aspects of patient care are addressed within the journal and practitioners from all disciplines are invited to submit their work. Areas covered include: Publication of audits; How an audit has changed practice;

Submit your manuscript here: http://www.dovepress.com/clinical-audit-journal

\section{Dovepress}

Practical tips on how to do audits and to avoid pitfalls; How audits have changed patient care; Calls and justifications for new audits. The manuscript management system is completely online and includes a very quick and fair peer-review system, which is all easy to use. Visit http://www.dovepress. com/testimonials.php to read real quotes from published authors. 